\title{
Implementation of a beating heart system for training in off-pump and minimally invasive coronary artery bypass
}

\author{
Shota Yasuda ${ }^{1,2^{*}+} \mathbb{D}$, Jef Van den Eynde ${ }^{1 \dagger}$, Katrien Vandendriessche ${ }^{1}$, Munetaka Masuda ${ }^{2}$, Bart Meyns ${ }^{1}$ \\ and Wouter Oosterlinck ${ }^{1}$
}

\begin{abstract}
Background: Several training devices have been developed to train anastomotic skills in off-pump coronary artery bypass grafting (OPCAB). However, assessment of trainees' improvement remains challenging. The goal of this study was to develop a new practical scoring chart and investigate its reliability and utility for anastomotic skills in OPCAB and minimally invasive direct coronary artery bypass (MIDCAB).
\end{abstract}

Methods: A training device was used, which included a beating heart model installed in a dedicated box. A soft plastic tube was used as the left anterior descending artery, and a porcine ureter was used as the left internal mammary artery. Five cardiac surgery fellows (Fellows, $>5$ year of surgical experience) and five residents or medical students (Residents, $\leq 5$ year of surgical experience) were enrolled for this study. Before and after training, skills were evaluated using a scoring chart that took into account anastomotic time, leakage, shape, flow measurement, and self-estimation.

Results: Mean total score of all trainees was $15.4 \pm 4.0$ at pre-training and $18.5 \pm 2.4$ at post-training $(P=0.05)$. Before training, there was a significant difference in the total score between Fellows and Residents (18.6 \pm 2.2 vs $12.2 \pm 2.4$ points, $\mathrm{P}=0.002)$, which disappeared after training ( $19.4 \pm 2.5 \mathrm{vs} 17.6 \pm 2.2$ points, $\mathrm{P}=0.262)$. Residents benefitted from training with improvements in their time, total score, score for time, score for flow and subtraction score; however, these effects were not seen in Fellows. The most evident training effect was improvement of self-estimation, which was also seen in Fellows.

Conclusions: Residents were most likely to derive benefit from these training models with regard to both efficiency and quality. Training models seem to have an important role in making surgeons feel more comfortable with the procedure.

Keywords: Simulation training, Program evaluation, Coronary artery bypass, Anastomosis

\section{Background}

Off-pump coronary artery bypass grafting (OPCAB) is a strategy for myocardial revascularization on a beating

\footnotetext{
*Correspondence: shorty@mtj.biglobe.ne.jp

+ Shota Yasuda and Jef Van den Eynde contributed equally to this work

${ }^{1}$ Department of Cardiovascular Diseases, Research Unit of Cardiac

Surgery, University Hospitals Leuven, Herestraat 49, 3000 Leuven, Belgium

Full list of author information is available at the end of the article
}

heart without the use of cardiopulmonary bypass. In experienced centers, OPCAB is associated with lower incidence of cerebral infarction, as well as lower need for hemodialysis and blood transfusion [1-3]. On the other hand, the technique is more challenging, and the learning curve for surgical trainees to perform an excellent anastomosis on a moving target should not be underestimated. As a result, centers with less experience tend to reduce 
the amount of anastomoses in order to simplify a complex operation. However, incomplete revascularization is associated with higher adverse cardiac event rates [4]. For this and other practical reasons, many hospitals prefer on-pump CABG, and the proportions of use between these two options have remained largely unchanged over the years [5]

Adequate technical skills training remains an essential part in the education of surgeons. Several training devices have been developed to train anastomotic skills on a beating heart model in a safe environment $[6,7]$. However, few of these systems have been evaluated systematically in various settings. There is a lack of simulations for minimally invasive coronary artery bypass (MIDCAB), which is performed through smaller incisions rather than a full sternotomy [8]. Furthermore, without an appropriate scoring chart, it is difficult to evaluate to what extent these simulations contribute to the learning process of trainees.

Further optimization of the available beating heart simulations might provide useful tools to train young surgeons and keep track of the evolution of their skills. The goal of this study was therefore to develop a new practical scoring chart and investigate its reliability and utility for anastomotic skills in OPCAB and MIDCAB.

\section{Methods}

This was a prospective, interventional cohort study of simulation as a training tool for acquisition of surgical skills. This study conforms to the ethical guidelines of the 1975 Declaration of Helsinki as reflected in a priori approval by the Medical Ethical Committee and Institutional Review Board (OG032) of the University Hospitals of KU Leuven (reference number ML10659). Training and testing took place at the Department of Cardiac Surgery of the University Hospitals of Leuven.

\section{Study subjects}

Five fellows with more than five years of experience after graduating medical school (Fellows) and five residents or medical students with five or less years of experience (Residents) were enrolled for this study. All fellows had some experience with anastomosis techniques for coronary arteries, whereas none of the residents had such experience.

\section{Study devices}

We used a beating heart model (CABG HEARTS\#1259; The Chamberlain group, Great Barrington, MA, USA) and installed it in a dedicated box (Fig. 1) to mimic the spatial limitations in OPCAB. Beating of the heart was created by a compressor that compressed the air and adjusted the pressure in the heart, and the frequency of

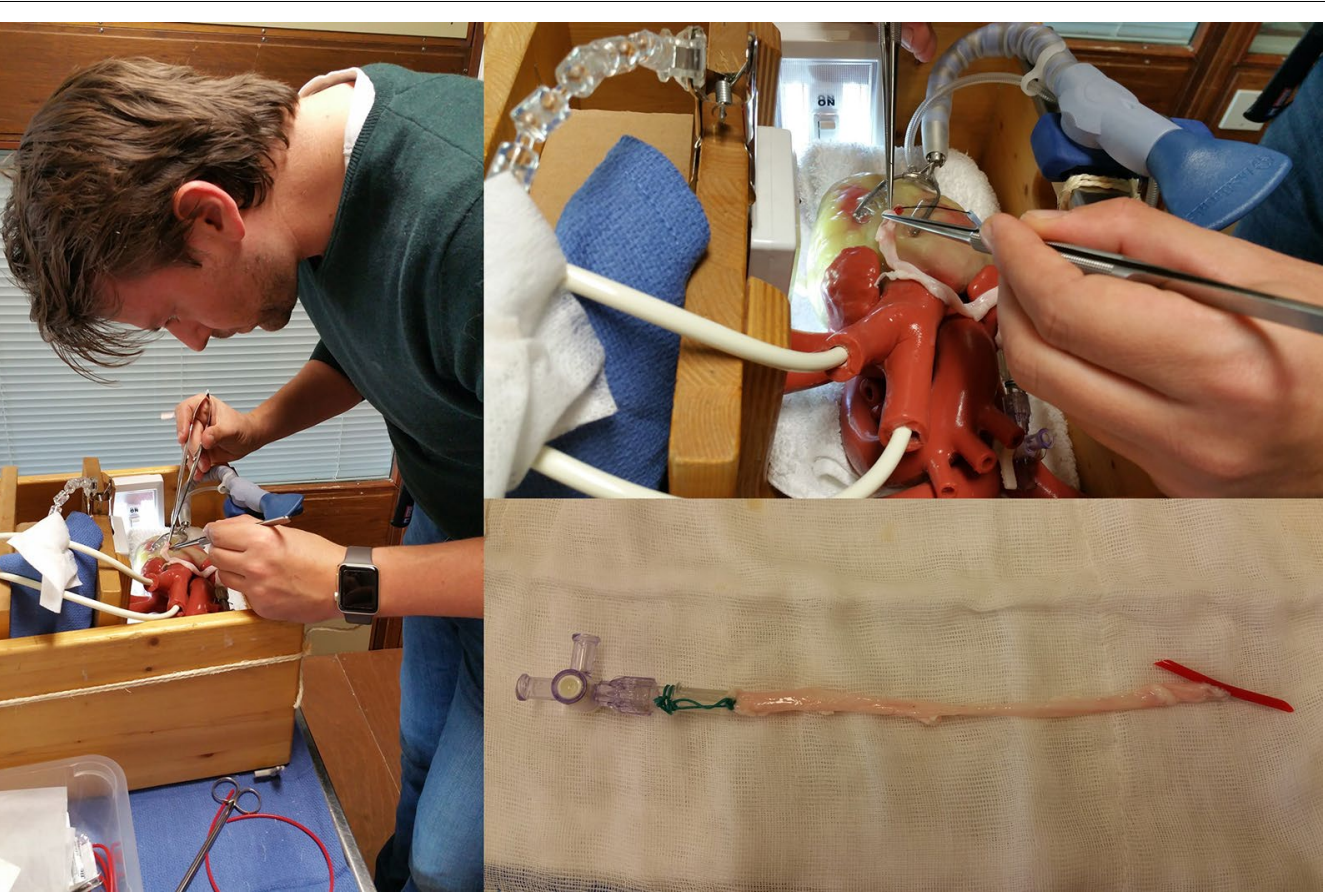

Fig. 1 (Left panel) Trainee performing an anastomosis. (Right upper panel) Anastomosis using a pig ureter and a soft plastic tube as the left internal mammary artery to the left anterior descending artery. (Right lower panel) The pig ureter graft after completion of anastomosis 
the beat was regulated by a dedicated regulator. A hollow soft plastic vessel loop (Ref. 18-474100-001, $1.5 \mathrm{~mm} \times$ $3 \mathrm{~mm} \times 1 \mathrm{~m}$, Nootens H.Ets, Schaerbeek, Belgium) was used as the target vessel and was inserted in the gutter of the beating heart model (Fig. 1). The vessel loop was expanded and softened by scraping it with emery-paper. Pig ureters were harvested and preserved in a freezer at - 80 degree Celsius; they were defrosted before practice and used as the grafts. An Octopus heart stabilizer (Medtronic Plc, Dublin, Ireland) was installed on the beating heart. Each trainee used the same graft in order to ensure the same graft conditions.

\section{Training design}

Trainees performed anastomoses from the left internal mammary artery to the left anterior descending artery with 8-0 polypropylene sutures and $1.75 \mathrm{~mm}$ shunt tubes (Fig. 1). The standard heart rate was set at $60 \mathrm{bpm}$. Following demonstration of the anastomosis technique by an expert (SY), trainees self-practiced the anastomosis independently at least three times. Before and after training, anastomotic skills were examined using a scoring chart (Table 1). All examinations were supervised and scored by SY.

\section{Scoring chart}

A new scoring chart was created to evaluate anastomotic skills based on clinically important parameters (Table 1). Items included: anastomotic time, leakage, shape, flow measurement, and self-estimation of the work. Each parameter was scored from 1 to 5 points (with 5 being full marks) and a total score was derived on a maximum of 25 points. Penalty points were given in case of issues with the shunt tube, or issues with the needle or thread ( -2 and -1 points, respectively). Issues with the shunt tube were defined as unexpected shunt tube removal or transfixation of the thread through the shunt, whereas issues with the needle or thread were defined as unexpected cutting of the needle, or knot formation in the thread.

\section{Evaluation of anastomosis quality}

The anastomotic site was evaluated after completion of the anastomosis. Saline was injected under $150 \mathrm{mmHg}$ pressure while clamping both sides of the plastic tube, and verified for leakage from the anastomotic site. One leakage corresponded with a single jet from the suture line, two leakages corresponded with two jets from two points. If leakage was present, additional stitches were placed to allow for precise flow measurement subsequently. Simultaneously, the outer shape of the anastomotic site was inspected. A flow measurement device with a $4 \mathrm{~mm}$ flow probe $(4 \mathrm{~mm}$ perivascular flow-probe PS series, Transonic Systems Inc. Ithaca, New York, USA) was used for the flow measurement after complete declamping of the proximal side of the plastic vessel loop (coronary artery), thus simulating a 100\% coronary artery stenosis and ruling out any effects attributable to competitive flow. Finally, the graft was cut and the inside of the anastomosis was inspected for the presence of stenosis.

\section{Statistical analysis}

Chart scores and time required for anastomosis were analyzed and compared between groups. Continuous variables were checked for normality and group differences were evaluated using t-test or Mann-Whitney $U$ test accordingly. Results are expressed as the mean $\pm \mathrm{SD}$. A 2-way ANOVA was used to evaluate the difference between groups in relation to time (before and after training). Spearman's rank correlation coefficient was used to evaluate the relationship between the change in time and change in score. All statistical analyses were performed using the SPSS software version 25 (SPSS Inc, Chicago, Illinois, USA). $P$ values less than 0.05 were considered to indicate statistical significance.

\section{Results \\ Effect of the training}

The mean total score of all trainees was $15.4 \pm 4.0$ at pretraining and $18.5 \pm 2.4$ at post-training $(\mathrm{P}=0.05)$. The

Table 1 Scoring chart

\begin{tabular}{|c|c|c|c|c|c|}
\hline & Time (min) & Leakage & Shape & Flow (ml/min) & Self-estimation \\
\hline 5 Points & $<8$ & None & Cobra head & $>200$ & Easy \\
\hline 4 Points & $8-12$ & Oozing & & $151-200$ & Relatively easy \\
\hline 3 Points & $12-16$ & 1 Point leakage & Stenosis & $101-150$ & Moderate \\
\hline 2 Points & $16-20$ & 2 Points leakage & & $51-100$ & Relatively difficult \\
\hline 1 Point & $20<$ & Dehiscence & Occlusion & $<50$ & Difficult \\
\hline-1 Point & \multicolumn{5}{|c|}{ Issues with the shunt tube } \\
\hline-2 Points & \multicolumn{5}{|c|}{ Issues with the needle or thread } \\
\hline
\end{tabular}


mean anastomotic time shortened from $21.1 \pm 7.4 \mathrm{~min}$ before training to $17.1 \pm 3.4 \mathrm{~min}$ after training $(P=0.144)$. Before training, there was a significant difference in the total score between the Fellows and Residents groups $(18.6 \pm 2.2$ vs $12.2 \pm 2.4$ points, $\mathrm{P}=0.002)$, which disappeared after training $(19.4 \pm 2.5$ vs $17.6 \pm 2.2$ points, $\mathrm{P}=0.262$ ) (Fig. 2). After training, there was a significant improvement of total score, anastomotic time, flow, and self-estimation in the Residents group, with a significant reduction of penalty points (Tables 2 and 3). Even after excluding self-estimation from the scoring system (thereby only preserving the objectively measured factors), a clear benefit for residents was observed. Fellows showed improved self-estimation after training, but no improvements on other parameters.

\section{Correlation between change in time and change in score}

Some degree of correlation between the change in time and change in score was noted (score $=1.75-0.34 *$ time, $\mathrm{R}^{2}=0.492$ ) (Fig. 3). Residents showed the most evident changes, whereas fellows did not show any marked improvement in their score or time after training.

\section{Discussion}

Technical skills training remains an essential part of surgical education. Simulation models are a promising tool, especially in procedures as challenging as OPCAB and MIDCAB. In this study, we used a beating heart model and developed a new score chart in order to further optimize training and make the learning process more trackable.

A first finding of our study was the significant difference in total score between the Fellows and Residents groups before training, which disappeared after training. Indeed, all Fellows had had experience with anastomotic techniques for coronary revascularization in the past. This suggests that our scoring chart might give an accurate estimation of trainees' initial skill level, and that every increase in their score might reflect improvement of skills. This allows supervisors to evaluate the level of knowledge when fellows or residents arrive at their department, which can facilitate individually tailored training. In addition, it allows monitoring of progress, which can be motivational for both trainees and supervisors.

In 2008, Fann et al. proposed a first performance rating score for coronary anastomosis on beating heart simulators [6]. The 8-item score was modified from the Objective Structured Assessment of Technical Skills (OSATS) described by Reznick et al. [9] and showed clear improvement on various technical aspects with training. However, the scoring system is complex and does not lend itself to quick periodic assessment. Furthermore, leakage, anastomosis shape, and intraoperative graft flow measurements are not accounted for in the score, although these represent major quality checks performed in real life surgery. In addition, trouble with the shunt tube and suture thread that can occur during surgery can lengthen the anastomotic time and reduce quality. Trainees' ability

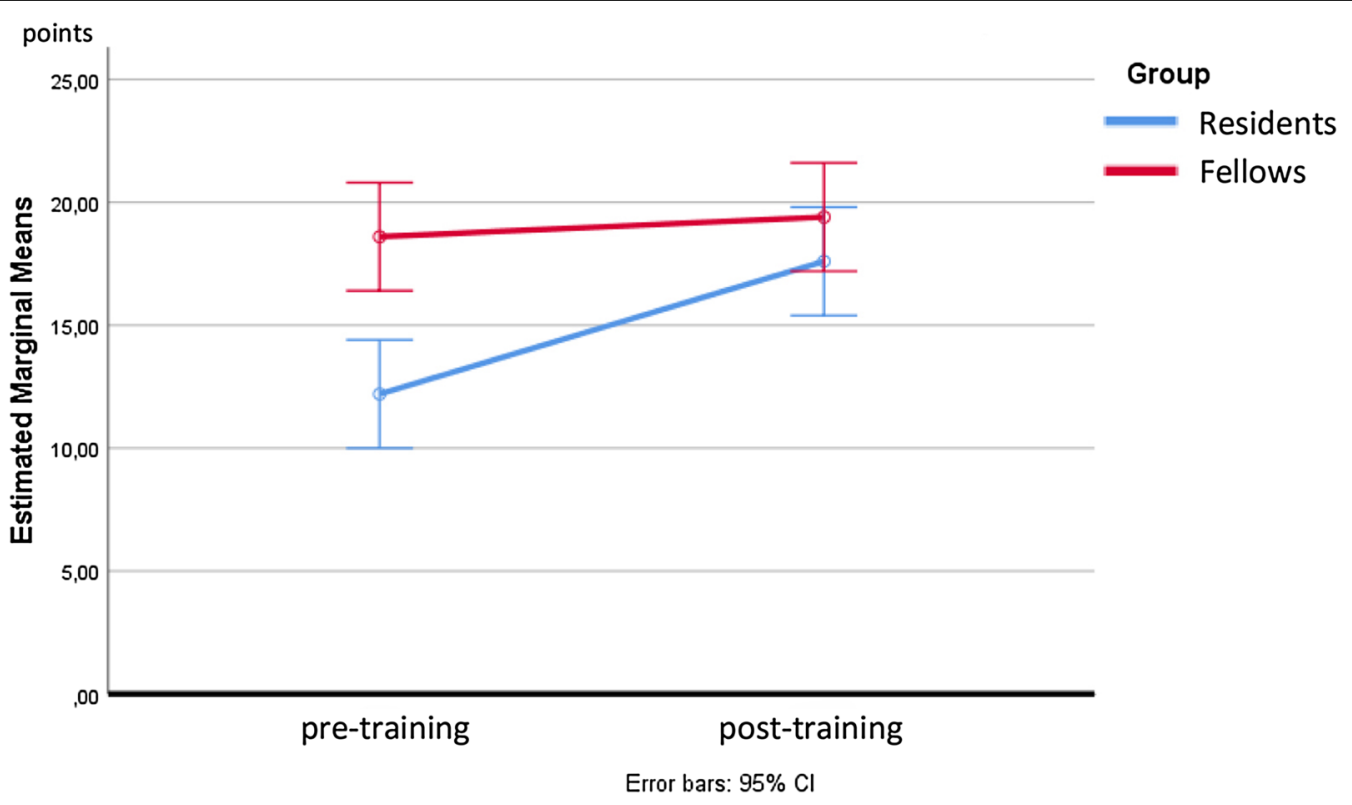

Fig. 2 Estimated marginal means of total score. No significant difference was evident after the training 
Table 2 Results of the pre- and post-training assessment of residents' and fellows' performance

\begin{tabular}{|c|c|c|c|c|c|c|}
\hline \multirow[t]{2}{*}{ Item } & \multirow[t]{2}{*}{ Group } & \multicolumn{2}{|l|}{ Performance } & \multicolumn{3}{|l|}{ 2-Way ANOVA } \\
\hline & & Pre-training & Post-training & Group effect & Training effect & $\begin{array}{l}\text { Group } x \\
\text { training } \\
\text { interaction }\end{array}$ \\
\hline \multirow[t]{2}{*}{ Time (min) } & Residents & $26.8 \pm 4.97$ & $17.6 \pm 2.51$ & $F(1,16)=11,544$ & $F(1,16)=4,805$ & $F(1,16)=8.12$ \\
\hline & Fellows & $15.4 \pm 3.97$ & $16.6 \pm 4.45$ & $P=0.004^{a}$ & $P=0.044^{a}$ & $P=0.012^{a}$ \\
\hline \multicolumn{7}{|l|}{ Score } \\
\hline \multirow[t]{2}{*}{ Total } & Residents & $12.2 \pm 2.39$ & $17.6 \pm 2.19$ & $F(1,16)=15,565$ & $F(1,16)=8,898$ & $F(1,16)=4,898$ \\
\hline & Fellows & $18.6 \pm 2.19$ & $19.4 \pm 2.51$ & $P=0.001^{a}$ & $P=0.009^{a}$ & $P=0.042^{a}$ \\
\hline \multirow[t]{2}{*}{ Time } & Residents & $1 \pm 0$ & $2 \pm 0.71$ & $F(1,16)=6.4$ & $F(1,16)=1.6$ & $F(1,16)=3.6$ \\
\hline & Fellows & $2.4 \pm 0.89$ & $2.2 \pm 0.84$ & $P=0.022^{a}$ & $P=0.224$ & $P=0.076$ \\
\hline \multirow[t]{2}{*}{ Leak } & Residents & $3.6 \pm 1.52$ & $3.4 \pm 1.14$ & $F(1,16)=0.036$ & $F(1,16)=0.036$ & $F(1,16)=0.321$ \\
\hline & Fellows & $3.2 \pm 1.1$ & $3.6 \pm 0.89$ & $P=0.852$ & $P=0.852$ & $P=0.579$ \\
\hline \multirow[t]{2}{*}{ Shape } & Residents & $4.2 \pm 1.1$ & $4.6 \pm 0.89$ & $F(1,16)=3.6$ & $F(1.16)=0,4$ & $F(1.16)=0,4$ \\
\hline & Fellows & $5 \pm 0$ & $5 \pm 0$ & $P=0.076$ & $P=0.536$ & $P=0.536$ \\
\hline \multirow[t]{2}{*}{ Flow } & Residents & $3.4 \pm 1.67$ & $4.8 \pm 0.45$ & $F(1,16)=4$ & $F(1,16)=2.25$ & $F(1,16)=4$ \\
\hline & Fellows & $5 \pm 0$ & $4.8 \pm 0.45$ & $P=0.063$ & $P=0.153$ & $P=0.063$ \\
\hline \multirow[t]{2}{*}{ Self-estimation } & Residents & $1 \pm 0$ & $2.8 \pm 0.45$ & $F(1,16)=103,143$ & $F(1,16)=48,286$ & $F(1,16)=7,143$ \\
\hline & Fellows & $3.4 \pm 0.55$ & $4.2 \pm 0.45$ & $P=0.000^{a}$ & $P=0.000^{a}$ & $P=0.017^{a}$ \\
\hline \multirow[t]{2}{*}{ Penalty points } & Residents & $-1 \pm 1$ & $0 \pm 0$ & $F(1,16)=0.095$ & $F(1,16)=2,381$ & $F(1,16)=2,381$ \\
\hline & Fellows & $-0.4 \pm 0.55$ & $-0.4 \pm 0.89$ & $P=0.762$ & $P=0.142$ & $P=0.142$ \\
\hline \multirow{2}{*}{$\begin{array}{l}\text { Total score excluding } \\
\text { self-estimation } \\
\text { Self sstimation }\end{array}$} & Residents & $11.2 \pm 2.39$ & $14.8 \pm 2.17$ & $F(1,16)=5.29$ & $F(1,16)=3,541$ & $F(1,16)=3,541$ \\
\hline & Fellows & $15.2 \pm 1.79$ & $15.2 \pm 2.17$ & $P=0.035^{a}$ & $P=0.078$ & $P=0.078$ \\
\hline
\end{tabular}

Number of subjects: fellows $=5$, residents $=5$

ANOVA analysis of variance

a Statistically significant, $\mathrm{P}<0.05$

to perform coronary anastomoses may therefore be more precisely represented by taking these frequent troubles into account when determining the score. The advantage of our scoring system is that it allows for a quick assessment, taking into account all factors that will determine bypass quality in real life.

In our study, residents were the most likely to derive benefit from these training models with regard to both efficiency (time, self-estimation) and quality (flow). The most evident training effect was improvement of selfestimation, which was also seen in fellows. This suggests that training models might have an important role in making surgeons feel more comfortable with the procedure, which is conducive to preparing them for more advanced surgical procedures in the operating theatre. Indeed, once a surgeon has gained self-confidence over one part of the procedure, less effort has to be invested in that part of the surgery and more energy will be available for other pats of the surgery which require attention. It is unclear why fellows' skills did not markedly improve with this training in our study. The system might not have been challenging enough, given their previous experience with anastomosis techniques. As the fellows were used to advanced surgical instruments and the specific conditions of a clinical operating theatre, adjusting to the specific experimental set-up could have attenuated their true improvement with training. However, as fellows did not obtain the maximum score, additional training could allow further monitoring and improvement of their level to an expert level.

A limitation of our study is that some features of CABG have not been included in our model: consideration of graft design, graft harvesting, creation of an operating field, fixation of the coronary artery with a stabilizer, and dissection and opening of the coronary artery $[10,11]$. All these techniques are mandatory for CABG in general and are not unique for OPCAB. However, given that the main difficulty of OPCAB compared to on-pump CABG lies in the need to operate on moving target vessels in a deep operating field, we are convinced that practicing an anastomosis within these specific conditions should receive major attention when training young surgeons to perform OPCAB. Furthermore, improved flows and bypass quality will benefit patient outcomes in both 
Table 3 Estimated effect of training for residents and fellows

\begin{tabular}{|c|c|c|c|c|}
\hline \multirow[t]{2}{*}{ Item } & \multirow[t]{2}{*}{ Group } & \multicolumn{3}{|c|}{ Estimated marginal means } \\
\hline & & Mean difference & P-value & $\begin{array}{l}\text { Partial } \eta \\
\text { squared }\end{array}$ \\
\hline \multirow[t]{2}{*}{ Time (min) } & Resident & $-9.2 \pm 2.58$ & $0.003^{\mathrm{a}}$ & 0.44 \\
\hline & Fellow & $1.2 \pm 2.58$ & 0.648 & 0.01 \\
\hline \multicolumn{5}{|l|}{ Score } \\
\hline \multirow[t]{2}{*}{ Total } & Resident & $5.4 \pm 1.47$ & $0.002^{\mathrm{a}}$ & 0.46 \\
\hline & Fellow & $0.8 \pm 1.47$ & 0.594 & 0.02 \\
\hline \multirow[t]{2}{*}{ Time } & Resident & $1 \pm 0.45$ & $0.04^{\mathrm{a}}$ & 0.24 \\
\hline & Fellow & $-0.2 \pm 0.45$ & 0.661 & 0.01 \\
\hline \multirow[t]{2}{*}{ Leak } & Resident & $-0.2 \pm 0.75$ & 0.793 & 0.00 \\
\hline & Fellow & $0.4 \pm 0.75$ & 0.6 & 0.02 \\
\hline \multirow[t]{2}{*}{ Shape } & Resident & $0.4 \pm 0.45$ & 0.384 & 0.05 \\
\hline & Fellow & $0 \pm 0.45$ & 1 & 0.00 \\
\hline \multirow[t]{2}{*}{ Flow } & Resident & $1.4 \pm 0.57$ & $0.025^{\mathrm{a}}$ & 0.28 \\
\hline & Fellow & $-0.2 \pm 0.57$ & 0.728 & 0.01 \\
\hline \multirow[t]{2}{*}{ Self-estimation } & Resident & $1.8 \pm 0.27$ & $0.000^{\mathrm{a}}$ & 0.74 \\
\hline & Fellow & $0.8 \pm 0.27$ & $0.008^{\mathrm{a}}$ & 0.36 \\
\hline \multirow[t]{2}{*}{ Penalty points } & Resident & $1 \pm 0.46$ & $0.044^{\mathrm{a}}$ & 0.23 \\
\hline & Fellow & $0 \pm 0.46$ & 1 & 0.00 \\
\hline \multirow{2}{*}{$\begin{array}{l}\text { Total score } \\
\text { excluding self- } \\
\text { estimation }\end{array}$} & Resident & $3.6 \pm 1.35$ & $0.017^{\mathrm{a}}$ & 0.31 \\
\hline & Fellow & $0 \pm 1.35$ & 1 & 0.00 \\
\hline
\end{tabular}

a Statistically significant, $\mathrm{P}<0.05$
OPCAB and on-pump CABG. Another limitation is that we only tested performance of LIMA-LAD anastomoses. For further practice, our model could be expanded to include also the evaluation of the circumflex and right coronary artery. Finally, our study only evaluated the effect of practice on the short term, whereas training usually takes place over a much longer period. However, here we aimed to evaluate the short-term efficacy of our training model and to validate our scoring system. Our institution is currently enrolling a randomized controlled trial to study the long-term efficacy of our training model.

Several training kits for CABG have been introduced, yet the issue of continuous costs remains $[8,12]$. In our training system, the only required investment is the beating heart system; all other material is mainly re-usable. The ureters of the pig are harvested as waste from other acute experiments, which avoids ethical issues as well as recurring additional costs.

The plastic tube is made of a relatively hard material which resembles atherosclerotic native vessels. It can be made softer by scraping the surface of the tube. Ureters of pigs have a tapered structure, where the distal side is slender and similar to an internal mammary artery and the proximal side is thick and like a saphenous vein graft. This combination of tubes and ureters allows for the replication of various situations for trainings.

Some reports maintained that on-the-job training for their fellows in cardiac surgery had a good result without

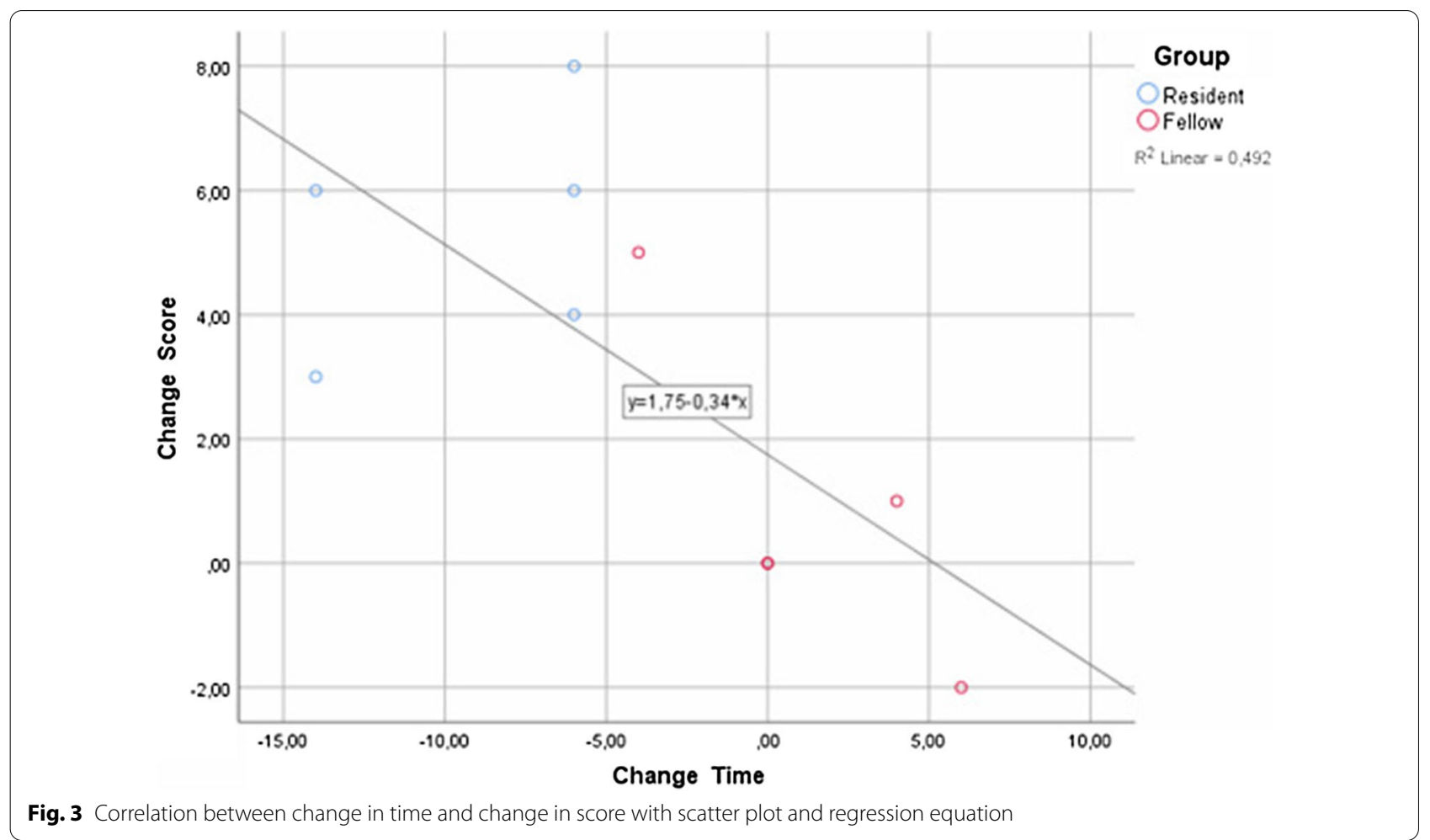




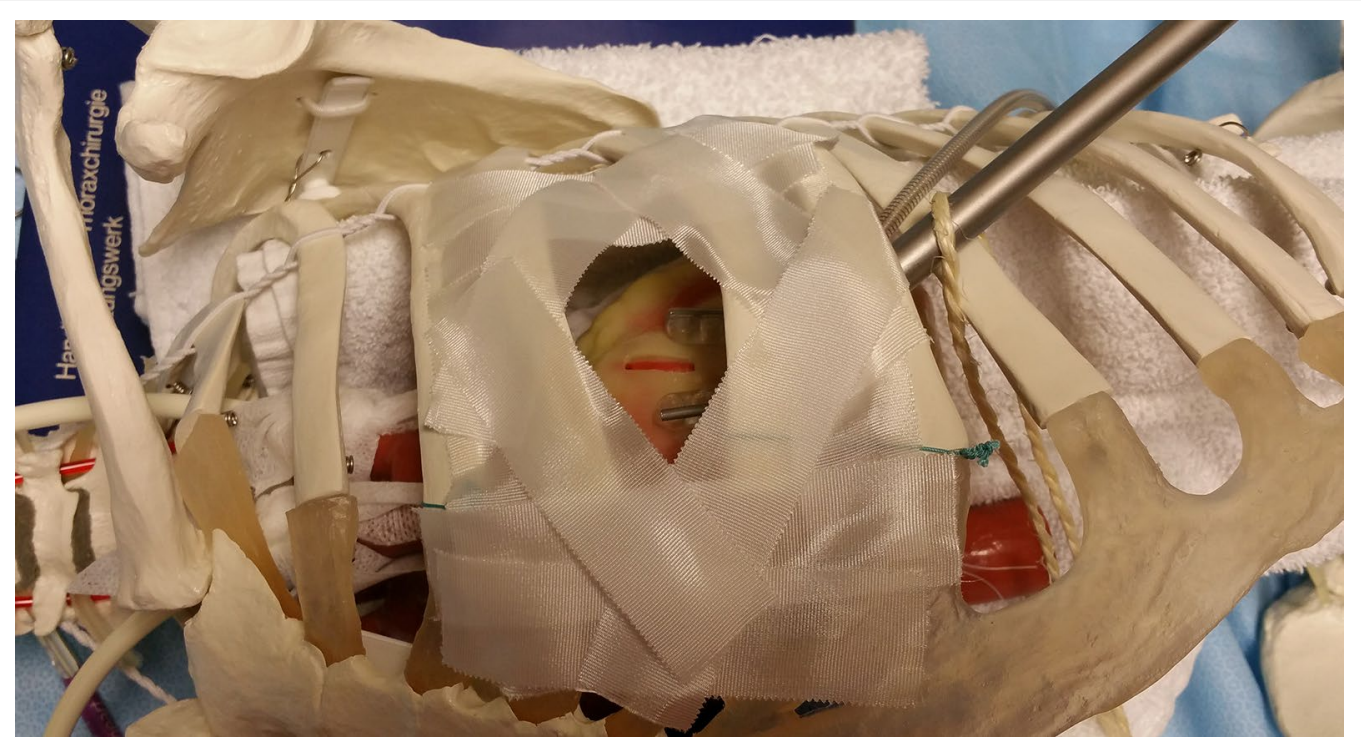

Fig. 4 MIDCAB training model using skeleton body

any increased mortality $[13,14]$. From an ethical perspective, however, this remains a difficult point, especially when the exact performance level of the trainee still needs to be determined. Time efficacy also requires that trainees are maximally prepared before they start working on living subjects. In addition, MIDCAB is receiving renewed focus with the advent of robotic surgery $[15,16]$ and the gained interest in hybrid approaches $[17,18]$. As an example, a novel option for cases of triple vessels disease is the performance of LIMA-LAD anastomosis by robotic assisted MIDCAB followed by percutaneous coronary intervention (PCI) for the other two coronary vessels [19] Given the limited space through a thoracotomy, young surgeons who are eager to become proficient in performing MIDCAB must practice coronary anastomosis using appropriate training devices, to obtain enough experience and ease so that they can perform adequately under high pressure and ensure proper bypass quality. To this purpose, we have developed a setting to our simulation specifically for MIDCAB using a skeleton model in which the beating heart can be placed (Fig. 4). This advanced device may allow fellows to engage in more effective trainings than is available at present and to give them additional challenging training goals.

\section{Conclusions}

In conclusion, this study showed that training on a beating heart model improved coronary anastomosis skills in residents and improved confidence about surgical performance in both residents and fellows. The training situation can be adapted to specifically represent features of OPCAB and MIDCAB. Furthermore, a new scoring chart was introduced, which might be useful for both quick initial assessment of new residents and tracking of their progress.

\section{Abbreviations}

CABG: Coronary artery bypass grafting; LAD: Left anterior descendens; LIMA: Left internal mammary artery; MIDCAB: Minimally invasive direct coronary artery bypass grafting; OPCAB: Off-pump coronary artery bypass grafting; OSATS: Objective structured assessment of technical skills; PCl: Percutaneous coronary intervention.

\section{Acknowledgements}

Not applicable.

\section{Authors' contributions}

SY, JVDE, KVDD, MM, BM and WO conceived the study. SY, JVDE, KVDD, and WO developed the training model and scoring chart. SY examined all residents and fellows before and after training. JVDE analyzed the data and performed statistical analyses. SY and JVDE drafted the manuscript. KVDD, MM, BM, and WO gave important intellectual contribution and critically revised the manuscript. All authors read and approved the final manuscript.

\section{Funding}

This research did not receive any specific grant from funding agencies in the public, commercial, or not-for-profit sectors.

\section{Availability of data and materials}

The datasets used and/or analyzed during the current study are available from the corresponding author on reasonable request.

\section{Ethics approval and consent to participate}

This study conforms to the ethical guidelines of the 1975 Declaration of Helsinki as reflected in a priori approval by the Medical Ethical Committee and Institutional Review Board (OG032) of the University Hospitals of KU Leuven (reference number ML10659).

\section{Consent for publication}

Not applicable. 


\section{Competing interests}

WO is proctor for minimally invasive multivessel MIDCAB at Medtronic. All other authors declare that they have no competing interests.

\section{Author details}

${ }^{1}$ Department of Cardiovascular Diseases, Research Unit of Cardiac Surgery, University Hospitals Leuven, Herestraat 49, 3000 Leuven, Belgium. ${ }^{2}$ Department of Surgery, Yokohama City University, 3-9 Fukuura, Kanazawa-ku, Yokohama, Kanagawa 2360004, Japan.

Received: 22 April 2020 Accepted: 20 December 2020

Published online: 06 January 2021

\section{References}

1. Sedrakyan A, Wu AW, Parashar A, Bass EB, Treasure T. Off-pump surgery is associated with reduced occurrence of stroke and other morbidity as compared with traditional coronary artery bypass grafting: a meta-analysis of systematically reviewed trials. Stroke. 2006;37(11):2759-69. https:// doi.org/10.1161/01.STR.0000245081.52877.f2.

2. Chawla LS, Zhao Y, Lough FC, Schroeder E, Seneff MG, Brennan JM. Offpump versus on-pump coronary artery bypass grafting outcomes stratified by preoperative renal function. J Am Soc Nephrol. 2012;23:1389-97. https://doi.org/10.1681/ASN.2012020122.

3. Zhao DF, Edelman JJ, Seco M, Bannon PG, Wilson MK, Byrom MJ, Thourani V, Lamy A, Taggart DP, Puskas JD, Vallely MP. Coronary artery bypass grafting with and without manipulation of the Ascending Aorta: a network meta-analysis. J Am Coll Cardiol. 2017;69:924-36. https://doi. org/10.1016/j.jacc.2016.11.071.

4. Hattler B, Messenger JC, Shroyer AL, Collins JF, Haugen SJ, Garcia JA, Baltz JH, Cleveland JC Jr, Novitzky D, Grover FL, Veterans Affairs Randomized On/Off Bypass (ROOBY) Study Group. Off-Pump coronary artery bypass surgery is associated with worse arterial and saphenous vein graft patency and less effective revascularization: results from the Veterans Affairs Randomized On/Off Bypass (ROOBY) trial. Circulation. 2012;125:2827-35. https://doi.org/10.1161/CIRCULATIONAHA.111.06926 0.

5. D'Agostino RS, Jacobs JP, Badhwar V, Fernandez FG, Paone G, Wormuth DW, Shahian DM. The society of thoracic surgeons adult cardiac surgery database: 2018 update on outcomes and quality. Ann Thorac Surg. 2018;105:15-23. https://doi.org/10.1016/j.athoracsur.2017.10.035.

6. Fann JI, Caffarelli AD, Georgette G, Howard SK, Gaba DM, Youngblood P, Mitchell RS, Burdon TA. Improvement in coronary anastomosis with cardiac surgery simulation. J Thorac Cardiovasc Surg. 2008;136:1486-91. https://doi.org/10.1016/j.jtcvs.2008.08.016

7. Park YK, Mita Y, Oki E, Kanemitsu N, Shiraishi Y, Ishii Y, Azuma T, Ochi M, Umezu M. Quantitative evaluation for anastomotic technique of coronary artery bypass grafting by using in-vitro mock circulatory system. Conf Proc IEEE Eng Med Biol Soc. 2007;2007:2705-8. https://doi.org/10.1109/ IEMBS.2007.4352887.

8. Bouma W, Kuijpers M, Bijleveld A, De Maat GE, Koene BM, Erasmus ME, Natour E, Mariani MA. A new beating-heart off-pump coronary artery bypass grafting training model. Interact Cardiovasc Thorac Surg. 2015;20:7-9. https://doi.org/10.1093/icvts/ivu321.

9. Reznick R, Regehr G, MacRae H, Martin J, McCulloch W. Testing technical skill via an innovative "bench station" examination. Am J Surg. 1997;173:226-30. https://doi.org/10.1016/s0002-9610(97)89597-9.

10. Hart JC, Puskas JD, Sabik JF 3rd. Off-pump coronary revascularization: current state of the art. Semin Thorac Cardiovasc Surg. 2002;14:70-81. https ://doi.org/10.1053/stcs.2002.31897.

11. Gründeman PF, Borst C, van Herwaarden JA, Verlaan CW, Jansen EW. Vertical displacement of the beating heart by the octopus tissue stabilizer: Influence on coronary flow. Ann Thorac Surg. 1998;65:1348-52. https:// doi.org/10.1016/s0003-4975(98)00226-4

12. Liu X, Yang Y, Meng Q, Sun J, Luo F, Cui Y, Zhang H, Zhang D, Tang Y. A secure and high-fidelity live animal model for off-pump coronary bypass surgery training. J Surg Educ. 2016;73:583-8. https://doi.org/10.1016/j. jsurg.2016.02.004

13. Smith TA, Asimakopoulos G. How safe is it to train residents to perform off-pump coronary artery bypass surgery? Interact Cardiovasc Thorac Surg. 2015;20:658-61. https://doi.org/10.1093/icvts/ivu447.

14. Murzi M, Caputo M, Aresu G, Duggan S, Angelini GD. Training residents in off-pump coronary artery bypass surgery: a 14-year experience. J Thorac Cardiovasc Surg. 2012;143:1247-53. https://doi.org/10.1016/j.jtcvs 2011.09.049.

15. Boulemden A, Pettinari M. Robotic-assisted minimally invasive direct coronary artery bypass grafting in single vessel disease. Multimed Man Cardiothorac Surg. 2019. https://doi.org/10.1510/mmcts.2019.011.

16. Giambruno V, Chu MW, Fox S, Swinamer SA, Rayman R, Markova Z, Barnfield R, Cooper M, Boyd DW, Menkis A, Kiaii B. Robotic-assisted coronary artery bypass surgery: an 18-year single-centre experience. Int J Med Robot. 2018;14:e1891. https://doi.org/10.1002/rcs.1891.

17. Puskas JD, Halkos ME, DeRose JJ, Bagiella E, Miller MA, Overbey J, Bonatti J, Srinivas VS, Vesely M, Sutter F, Lynch J, Kirkwood K, Shapiro TA, Boudoulas KD, Crestanello J, Gehrig T, Smith P, Ragosta M, Hoff SJ, Zhao D, Gelijns AC, Szeto WY, Weisz G, Argenziano M, Vassiliades T, Liberman H, Matthai W, Ascheim DD. Hybrid coronary revascularization for the treatment of multivessel coronary artery disease: a multicenter observational study. J Am Coll Cardiol. 2016;68:356-65. https://doi.org/10.1016/j. jacc.2016.05.032

18. Harskamp RE, Bagai A, Halkos ME, Rao SV, Bachinsky WB, Patel MR, de Winter RJ, Peterson ED, Alexander JH, Lopes RD. Clinical outcomes after hybrid coronary revascularization versus coronary artery bypass surgery: a meta-analysis of 1,190 patients. Am Heart J. 2014;167:585-92. https:// doi.org/10.1016/J.AHJ.2014.01.006.

19. Gao C, Yang M, Wu Y, Wang G, Xiao C, Liu H, Lu C. Hybrid coronary revascularization by endoscopic robotic coronary artery bypass grafting on beating heart and stent placement. Ann Thorac Surg. 2009;87:737-41. https://doi.org/10.1016/j.athoracsur.2008.12.017.

\section{Publisher's Note}

Springer Nature remains neutral with regard to jurisdictional claims in published maps and institutional affiliations.

Ready to submit your research? Choose BMC and benefit from

- fast, convenient online submission

- thorough peer review by experienced researchers in your field

- rapid publication on acceptance

- support for research data, including large and complex data types

- gold Open Access which fosters wider collaboration and increased citations

- maximum visibility for your research: over $100 \mathrm{M}$ website views per year

At BMC, research is always in progress.

Learn more biomedcentral.com/submissions 